\title{
REGULATION OF NITRIC OXIDE PRODUCTION IN HEALTH AND DISEASE
}

\author{
Yvette C. Luiking, PhD, Mariëlle P.K.J. Engelen, PhD, and Nicolaas E.P. Deutz, MD, PhD \\ Center for Translational Research in Aging \& Longevity. Donald W. Reynolds Institute on Aging. \\ University of Arkansas for Medical Sciences, Little Rock, U.S.A.
}

\begin{abstract}
Purpose of review-The purpose of this review is to highlight recent publications examining Nitric Oxide (NO) production in health and disease and its association with clinical nutrition and alterations in metabolism.
\end{abstract}

Recent findings-The role of the cofactor tetrahydrobiopterin (BH4) in NO production and its relation with arginine availability is indicated as an important explanation for the arginine paradox. This offers potential for NO regulation by dietary factors like arginine or its precursors and vitamin C. Because diets with a high saturated fat content induce high plasma fatty acid levels, endothelial NO production is often impaired due to a reduction in NOS3 phosphorylation. Increasing the arginine availability by arginine therapy or arginase inhibition was therefore proposed as a potential therapy to treat hypertension. Recent studies in septic patients and transgenic mice models found that inadequate de novo arginine production from citrulline reduces NO production. Citrulline supplementation may therefore be a novel therapeutic approach in conditions of arginine deficiency.

Summary-Both lack and excess of NO production in diseases can have various important implications in which dietary factors can play a modulating role. Future research is needed to expand our understanding of the regulation and adequate measurement of NO production at the organ level and by the different NOS isoforms, also in relation to clinical nutrition.

\section{Keywords}

nitric oxide; arginine; dietary factors; health; disease

\section{INTRODUCTION}

Nitric oxide (NO) is a widespread signaling molecule that participates in virtually every cellular and organ function in the body (for an historic perspective see [1]. The purpose of this review is to highlight recent studies relating NO production in health and disease to clinical nutrition and metabolism. We provide the latest insight in the mechanisms that regulate NO production under various conditions and the potential options for nutritionbased therapy. Outside the scope of the review are the factors that influence bioavailability of NO by scavenging, or inactivation via hemoglobin, superoxide, or oxidation [2].

Correspondence to: Nicolaas EP Deutz, MD, PhD. Center for Translational Research in Aging \& Longevity. Room \#3.121. Donald W. Reynolds Institute on Aging. University of Arkansas for Medical Sciences. 4301 W. Markham St. Slot 807, Little Rock, AR 72205, U.S.A.nep.deutz@ctral.org. 


\section{NO PRODUCTION}

NO is a highly reactive molecule, which complicates its direct measurements. Moreover, NO is produced at various locations in the body. Furthermore, NO production involves different enzyme isoforms and non-enzymatic pathways. All this adds to the various roles of NO in (patho)physiology as will be outlined below.

\section{NO metabolism and NOS isoforms (summarized in figure 1)}

Endogenous NO is derived largely from enzymatic pathways, but a non-enzymatic pathway also exists. Enzymatic NO formation is catalyzed by NO synthase (NOS) through a series of redox reactions, with degradation of L-arginine to L-citrulline and $\mathrm{NO}$, and in the presence of oxygen and NADPH $[3,4]$. Three isoforms of NOS are recognized: endothelial NOS (eNOS or NOS3), neuronal NOS (nNOS or NOS1) and inducible NOS (iNOS or NOS2). NOS1 and NOS3 are constitutive enzymes that are controlled by intracellular $\mathrm{Ca}^{2+} /$ calmodulin; NOS2 is inducible at the level of gene transcription, $\mathrm{Ca}^{2+}$ independent, and expressed by macrophages and other tissues in response to (pro)inflammatory mediators. A mitochondrial NOS isoform (mtNOS) is still under debate. Tetrahydrobiopterin (BH4) is an essential cofactor for NOS; BH4 is synthesized from GTP via the GTP-cyclohydrolase-I (GTP-CH) pathway. Other cofactors are flavin adenine dinucleotide (FAD), flavin mononucleotide (FMN) and heme (for recent reviews see [5,6]).

The non-enzymatic production of NO involves production of NO from nitrite via multiple pathways, particularly under acidic conditions (eg following ischemia) [7], and occurs mainly in tissue [8]. The main pathway is via nitrite reduction: $\mathrm{e}^{-}+2 \mathrm{H}^{+}+\mathrm{NO}_{2}{ }^{-} \rightarrow \mathrm{NO}+$ $\mathrm{H}_{2} \mathrm{O}$. Under ischemic conditions with acidosis, nitrite-mediated $\mathrm{NO}$ production approaches that of maximum constitutive NOS production, making this route an alternative under ischemic conditions in which NO production from NOS is impaired [8].

\section{Role of NO in Physiology and Pathophysiology}

NO is a key molecule involved in a variety of biological functions throughout the whole body [4]. In the vasculature, NO (major part from NOS3, but NOS1 is present around arterioles) regulates vascular tone and blood flow by activating soluble guanylate cyclase (sGC) in the vascular smooth muscle. Moreover, it is essential for leucocyte adhesion and platelet aggregation, and it controls mitochondrial oxygen consumption by inhibiting cytochrome c oxydase. Abnormalities in vascular NO production and transport result in endothelial dysfunction with various cardiovascular pathologies like hypertension, atherosclerosis and angiogenesis-associated disorders (for recent review see [5]). Interestingly, NOS3 can generate superoxide when the concentrations of either L-arginine or BH4 are low. This "uncoupling" of NOS3 occurs in several pathologies, like diabetes, hypercholesterolaemia and hypertension [9]. NO production was also suggested as a major inherited factor of insulin sensitivity, with diet-induced oxidative scavenging of $\mathrm{NO}$ as a first hit towards insulin resistance [10]. Recently, a higher NO production in pregnant Indian women with a low body mass index (BMI) was reported [11]. NO in the brain regulates many physiological processes affecting behavior and cognitive function, including synaptic plasticity. In addition, it also controls brain blood flow, promotes angiogenesis, maintains cellular redox state, cell immunity and neuronal survival. Its over-production may lead to neurodegeneration [12].

NO from NOS2 was originally identified in macrophages and contributes to the cytotoxic actions of these cells. NO produced by NOS2 in the vasculature is involved in the profound vasodilatation of septic shock [4]. Moreover, as a result of oxidative stress, cellular respiration is inhibited and tissues become unable to utilize available oxygen, called 
metabolic hypoxia. This might not be exclusive to septic shock but could also contribute to other inflammatory and degenerative conditions [13]. NO generated by NOS2 promotes atherosclerosis either directly or via the formation of NO adducts, such as peroxynitrite [1].

\section{Measurement of NO production}

The half-life of NO in blood is very short $(<1 \mathrm{sec})$ due to rapid oxidation by oxyhemoglobin to nitrate and nitrite (cumulatively indicated as NOx), binding of $\mathrm{NO}$ to several cell structures or $\mathrm{NO}$ scavenging. Therefore, $\mathrm{NO}$ in vivo is often measured as the concentration of its metabolites (NOx), as a surrogate indicator of NO production. NOx can be measured in plasma or within cells (eg polymorphonuclear neutrophils, [14]), or even in saliva, where it is partly derived from bacterial NO production in the oral cavity [15]. NOx analysis is widely available and relatively easy, but can be biased by dietary nitrate intake, renal clearance rate or (gut) bacterial production. For a recent review on nitrite/nitrate analysis, see [16]. Measurement of NO in exhaled air is also relatively easy and used as a marker for pulmonary inflammation. However, the shape of the exhaled NO profile is affected by variability in ventilation and NO production, as seen in asthmatic patients following an exercise challenge, which may impact the physiological interpretation [17].

A more sophisticated and more direct method is the measurement of NO production as the conversion of intravenous or orally administered stable-isotope labeled arginine (e.g. L$\left[{ }^{15} \mathrm{~N}_{2}{ }^{2} \mathrm{H}_{2}\right]$ - or L- $\left[{ }^{15} \mathrm{~N}_{2}\right]$-guanidino-arginine) to labeled NO metabolites $\left({ }^{15} \mathrm{NOx}\right) .{ }^{15} \mathrm{NOx}$ can be measured in urine by sampling over a certain time period with correction for creatinine excretion after bolus tracer infusion $\left[10,18^{*}, 19\right]$; alternatively, fractional or absolute synthetic rate can be measured in plasma/whole blood during steady state arginine tracer infusion [20,21]. Another approach is measurement of the conversion of labeled arginine to citrulline (L-[ureido- ${ }^{15} \mathrm{~N}-{ }^{2} \mathrm{H}_{2}$ ] - or L-[ureido- ${ }^{15} \mathrm{~N}$ ] -citrulline), which is produced concomitantly with NO. Simultaneous infusion of labeled citrulline (e.g. L- $\left[{ }^{2} \mathrm{H}_{2}\right]$ - or L$\left[{ }^{13} \mathrm{C}\right]$ - or L- $\left[{ }^{13} \mathrm{C}-{ }^{2} \mathrm{H}_{2}\right]-$ or L- $\left[{ }^{13} \mathrm{C}-{ }^{2} \mathrm{H}_{4}\right]$-citrulline) and arterial blood sampling enables the calculation of the absolute rate of whole body NO production. The latter method was first introduced by Castillo et al. [22] and has since been used by several groups under various conditions, including recent studies in neonates [23], patients with sepsis [24**,25**] and mice $[26,27]$. Analytical aspects involve the combination of gas or liquid chromatography and mass spectrometry to measure isotopic enrichments [28].

Discrepancies between NO production as measured by NOx and stable isotopes, however, exist and question the validity of the techniques. An increase in NOx with no concomitant increase in (stable isotope measured) NO production $\left[24^{* *}, 25^{* *}\right]$ may be due to altered renal function, extracellular volume changes or delayed conversion of NO to nitrate. On the other hand, NO production as measured by stable isotopes may not account for possible intracellular/organ compartmentalization and therefore underestimate NO production [29]. The direct conversion of citrulline to arginine and subsequently to NO (citrulline-NO cycle) in macrophages [30] or endothelial cells, [31], as well as urea metabolism or compartmentalized NO production from protein-derived arginine [27] are examples of compartmentalization. Therefore, the measured NO production probably represents minimal NO production. NO production rate measured with stable isotopes also varies: between 0.15 and $2.2 \mu \mathrm{mol} / \mathrm{kg}$.h in healthy subjects, between 0.14 and $0.25 \mu \mathrm{mol} / \mathrm{kg} . \mathrm{h}$ in pregnant Indian women and between 0.20 and $0.80 \mu \mathrm{mol} / \mathrm{kg}$.h in patients with sepsis (reviewed in [29]) $\left[11,24^{* *}, 25^{* *}\right]$. Differences in isotopes, equations and analytical techniques may underlie this variation, but make it difficult to compare absolute values of NO production between studies.

In tissue samples or in cells, total amounts of NOS proteins (from different isoforms) or NOS activities have been measured as indicators of tissue-specific NO production [32]. 
Moreover, activity of GTP-CH and concentrations of BH4 and NADPH play a role in modulating NOS activity and as such facilitate NO production [32]. The specificity of NOS1 or NOS3 activation can be indicated by the specific site of enzyme (de)phosphorylation [32]. Differences between animal species also exist, like for LPS-induced NO production by macrophages [33].

\section{REGULATION OF NO PRODUCTION IN HEALTH}

NO production is dependent on the availability of its precursor arginine and activity of the various NOS enzymes. Activity of the various NOS enzymes can also be affected by factors that influence the concentration of NOS proteins and cofactors (including BH4, NADPH, $\mathrm{Ca}^{2+}$ ), or alter NOS expression and kinetic properties. Related to the non-enzymatic nitrite$\mathrm{NO}$ pathway, $\mathrm{pH}$, oxygen tension, nitrite and reducing substrate concentration affect $\mathrm{NO}$ generation [8]. Dietary factors that regulate NO production are described below and summarized in Table 1.

\section{Dietary factors that regulate NO production (see figure 1)}

Dietary factors that regulate NO production include substrate (arginine) availability and others that affect NOS activity.

Substrate (arginine) availability-At normal concentrations of arginine, NOS3 should be saturated. However, increased NOS3 activity occurs with arginine supplementation, known as the arginine paradox, due to enhanced L-arginine induced $\mathrm{BH} 4$ production with promotion of NO production by NOS3 [37]. Plasma arginine availability can thus affect NO production, confirmed by the positive correlation shown in mice models [26]. Arginine availability is influenced by its dietary intake and endogenous production (protein breakdown and de novo synthesis from citrulline), as well as by arginine clearance (by arginase and protein synthesis) [3]. Arginase reciprocally regulates NO levels in endothelial cells by competing with NOS for the substrate L-arginine [43]. The intracellular transport of arginine by the cationic amino acid transporter and the competition with lysine also determines its availability as a precursor for NO [39]. In studies in mice that express only $5-10 \%$ of OTC activity, resulting in impaired citrulline availability and de novo arginine production, NO production was reduced; supplementation of citrulline or urea cycle intermediates was proposed to sustain NO production [26,27]. The close coupling between citrulline with de novo arginine synthesis pathway on the one hand and NO production on the other hand is also indicated by the co-localization in endothelial cells of NOS3 with the enzymes argininosuccinate synthase (ASS) and argininsuccinate lyase (ASL) [31]. The authors therefore proposed that both ASS and ASL could be therapeutic targets for modulating endothelial NO production [31]. The interorgan exchange of ornithine might play a crucial role to support citrulline production by the small intestine [27]. Direct postprandial utilization of meal arginine for NO production was considered to be low [19].

Other dietary factors that affect NOS activity-Wu et al [35] and Li et al [34] extensively reviewed regulation of NO production by single dietary factors. These dietary factors are either beneficial to health or contribute to the pathogenesis of chronic diseases, partially through modulation of NO production by inducible NOS or constitutive NOS [35]. A high-fat (palmitate) diet with high levels of free fatty acids resulted in lower arterial NOS3 phosphorylation, hypertension and vascular dysfunction as a result of free fatty acidmediated impairment of NOS3 phosphorylation and NO production [41**]. Dietary DHA supplementation in neonatal piglets increased NOS activity and cofactors for NOS in brain, liver and muscle, while dietary cholesterol only increased NOS activity in the brain [32]. 
Related to complex dietary factors, a meal challenge with high sucrose and high fat in rats decreased whole body NO production and NO-mediated vascular response, strongly related to plasma triglyceride levels [18*]. Diet-induced insulin release stimulates NO production in endothelial cells by increasing the production of NADPH and BH4 in endothelial cells, which may modulate tissue blood flow [37]. This insulin effect may be the result of a larger fraction of arginine flux converted to NOx, since arginine flux is even reduced during acute hyperinsulinemia [21].

\section{REGULATION OF NO PRODUCTION IN DISEASE}

Diseases can be characterized either by lack or excess of NO, as described above under pathophysiology. Protection against a decrease in constitutive NO production in the vasculature may prevent the development of vascular disease, while inhibition of excessive inducible NO production could also be a therapeutic target. Latest insights in NO production in diseases and underlying mechanism that offer therapeutic options are outlined below and also summarized in Table 1.

\section{Mechanisms affecting NO production in disease}

NO production is affected in sepsis and trauma, undernutrition and vascular disease and other diseases.

Sepsis and trauma-NO production, as measured by the conversion of stable isotope labeled arginine to citrulline, was equal or even lowered in patients with sepsis [24**,25**]. Despite the increased protein breakdown, arginine flux was similar but plasma arginine was lower. This seems attributed to increased plasma arginine clearance [24**] and inadequate de novo arginine production secondary to reduced citrulline production [25**]. It was therefore suggested that increasing arginine availability by arginine or citrulline supplementation might restore the arginine balance and NO production [24**,25**].

In an in vitro model of macrophages, arginine availability was a limiting factor for NO production, measured as nitrite concentration. However, citrulline was a potential substitute to restore NO production in the arginine-deprived environment, while glutamine interfered with citrulline-mediated NO production [38]. The authors therefore suggested that, in conditions of arginine deficiency (such as trauma or after surgery), citrulline supplementation might be a powerful way to restore NO production. Glutamine administration could be a mechanism to control excessive NO production by macrophages (authors proposed sepsis) [38]. In a mice model with reduced OTC activity (and thus citrulline production), treatment with LPS stimulated protein breakdown with maintenance of NO production [26].

Plasma levels of the endogenous NOS inhibitor $\mathrm{N}^{\mathrm{G}}$-methyl-L-arginine (ADMA) showed a wider range in patients with sepsis compared to healthy controls, but were not related to NO production, protein breakdown or renal and liver function [24**]. On the other hand, however, higher ADMA levels were related to higher mortality in sepsis [24**,44].

Undernutrition in children and neonates-In children with edematous severe undernutrition, NO production (as measured by urinary ${ }^{15} \mathrm{NOx}$ after labeled arginine infusion) was not different from the recovery state, while both plasma arginine and arginine flux were lowered [20]. An arginine-deficient diet in neonatal pigs reduced NO production, which suggests that arginine availability, probably largely controlled by the splanchnic area, drives NO production [23]. 
Vascular disease-Arginase has been proposed as an attractive therapy in modifying the arterial response to injury and may offer therapeutic interventions in the treatment of vascular disease (for review see [45]). However, a moderate increase in arginase I plasma level did not affect plasma arginine and major changes in arginase levels are probably needed to induce potential clinically relevant effects [46]. Pharmacological inhibition of arginase activity with $\mathrm{N}^{\omega}$-hydroxy-nor-L-arginine in a rat model of spontaneous hypertension increased NO production ( $\mathrm{NOx}$ ) with reduced blood pressure and improved reactivity of resistance vessels [47]. However, the effect was not completely NO mediated, since NOS inhibition did not fully abolish the effect of the arginase inhibitor. The authors proposed selective arginase inhibition as a potential new therapeutic strategy against hypertension [47]. Moreover, L-arginine was proposed as therapy in hypertension, to interrupt the vicious cycle that initiates and maintains low NO [36].

Of the various cardiovascular risk factors studied, homocysteine levels show a strong inverse relation with $\mathrm{NO}$ production, as measured by the urinary $\left[{ }^{15} \mathrm{~N}\right]$-nitrate excretion derived from labeled arginine [40], specifically by NOS3 [35]. Decreased NO production resulting from a deficiency in $\mathrm{BH} 4$, contributes to the impaired action of insulin in the vasculature of obese and diabetic subjects [37].

\section{CONCLUSION}

Implications of disturbed NO production in diseases are various and depend on whether lack or excess of NO production occurs. Dietary factors potentially can modulate NO production. Substrate bioavailability is crucial, but citrulline supplementation may be a good alternative as arginine precursor. Future research that extends our understanding of the regulation and adequate measurement of NO production at the organ level and by the different NOS isoforms is needed to align with adequate therapy. Moreover, the interrelation between arginine, citrulline and glutamine in the regulation of NO production, as well as the interaction and possible synergy between various dietary factors that affect NO production need further study.

\section{Acknowledgments}

The work of this article was supported in part by National institute of General Medicinal Sciences Grant R-01GM-084447 (Optimal Amino Acid Nutrition in Sepsis) to N.E.P. Deutz and R.R. Wolfe.

\section{References}

1. Moncada S, Higgs EA. The discovery of nitric oxide and its role in vascular biology. Br J Pharmacol. 2006; 147 1:S193-201. [PubMed: 16402104]

2. Beckman JS, Koppenol WH. Nitric oxide, superoxide, and peroxynitrite: the good, the bad, and ugly. Am J Physiol. 1996; 271:C1424-37. [PubMed: 8944624]

3. Wu G, Morris SM Jr. Arginine metabolism: nitric oxide and beyond. Biochem J. 1998; 336(Pt 1):117. [PubMed: 9806879]

4. Moncada S, Higgs A. The L-arginine-nitric oxide pathway. N Engl J Med. 1993; 329:2002-12. [PubMed: 7504210]

5. Chen K, Pittman RN, Popel AS. Nitric oxide in the vasculature: where does it come from and where does it go? A quantitative perspective. Antioxid Redox Signal. 2008; 10:1185-98. [PubMed: 18331202]

6. Chen K, Popel AS. Nitric oxide production pathways in erythrocytes and plasma. Biorheology. 2009; 46:107-19. [PubMed: 19458414]

7. Zweier JL, Wang P, Samouilov A, Kuppusamy P. Enzyme-independent formation of nitric oxide in biological tissues. Nat Med. 1995; 1:804-9. [PubMed: 7585184] 
8. Li H, Cui H, Kundu TK, et al. Nitric oxide production from nitrite occurs primarily in tissues not in the blood: critical role of xanthine oxidase and aldehyde oxidase. J Biol Chem. 2008; 283:1785563. [PubMed: 18424432]

9. Cai H, Harrison DG. Endothelial dysfunction in cardiovascular diseases: the role of oxidant stress. Circ Res. 2000; 87:840-4. [PubMed: 11073878]

10. Blouet C, Mariotti F, Mathe V, et al. Nitric oxide bioavailability and not production is first altered during the onset of insulin resistance in sucrose-fed rats. Exp Biol Med (Maywood). 2007; 232:1458-64. [PubMed: 18040070]

11. Kurpad AV, Kao C, Dwarkanath P, et al. In vivo arginine production and nitric oxide synthesis in pregnant Indian women with normal and low body mass indices. Eur J Clin Nutr. 2009

12. Moncada S, Bolanos JP. Nitric oxide, cell bioenergetics and neurodegeneration. J Neurochem. 2006; 97:1676-89. [PubMed: 16805776]

13. Moncada S, Erusalimsky JD. Does nitric oxide modulate mitochondrial energy generation and apoptosis? Nat Rev Mol Cell Biol. 2002; 3:214-20. [PubMed: 11994742]

14. Sureda A, Cordova A, Ferrer MD, et al. Effects of L-citrulline oral supplementation on polymorphonuclear neutrophils oxidative burst and nitric oxide production after exercise. Free Radic Res. 2009:1-8. [PubMed: 19750403]

15. Sato EF, Choudhury T, Nishikawa T, Inoue M. Dynamic aspect of reactive oxygen and nitric oxide in oral cavity. J Clin Biochem Nutr. 2008; 42:8-13. [PubMed: 18231624]

16. Bryan NS, Grisham MB. Methods to detect nitric oxide and its metabolites in biological samples. Free Radic Biol Med. 2007; 43:645-57. [PubMed: 17664129]

17. Suresh V, Shelley DA, Shin HW, George SC. Effect of heterogeneous ventilation and nitric oxide production on exhaled nitric oxide profiles. J Appl Physiol. 2008; 104:1743-52. [PubMed: 18356478]

*18. Magne J, Huneau JF, Delemasure S, et al. Whole-body basal nitric oxide production is impaired in postprandial endothelial dysfunction in healthy rats. Nitric Oxide. 2009; 21:37-43. [PubMed: 19416758] First study on postprandial NO production following a high saturated fat/high sucrose diet that was associated with reduced vascular reactivity. However, the mechanism requires further study.

19. Mariotti F, Huneau JF, Szezepanski I, et al. Meal amino acids with varied levels of arginine do not affect postprandial vascular endothelial function in healthy young men. J Nutr. 2007; 137:1383-9. [PubMed: 17513395]

20. Jahoor F, Badaloo A, Villalpando S, et al. Arginine flux and intravascular nitric oxide synthesis in severe childhood undernutrition. Am J Clin Nutr. 2007; 86:1024-31. [PubMed: 17921380]

21. Tessari P, Coracina A, Puricelli L, et al. Acute effect of insulin on nitric oxide synthesis in humans: a precursor-product isotopic study. Am J Physiol Endocrinol Metab. 2007; 293:E776-82. [PubMed: 17551000]

22. Castillo L, Beaumier L, Ajami AM, Young VR. Whole body nitric oxide synthesis in healthy men determined from [15N] arginine-to-[15N]citrulline labeling. Proc Natl Acad Sci U S A. 1996; 93:11460-5. [PubMed: 8876157]

23. Urschel KL, Rafii M, Pencharz PB, Ball RO. A multitracer stable isotope quantification of the effects of arginine intake on whole body arginine metabolism in neonatal piglets. Am J Physiol Endocrinol Metab. 2007; 293:E811-8. [PubMed: 17595215]

**24. Kao CC, Bandi V, Guntupalli KK, et al. Arginine, citrulline and nitric oxide metabolism in sepsis. Clin Sci (Lond). 2009; 117:23-30. [PubMed: 19105791] Clinical study in patients with sepsis using stable isotope techniques that, in line with the study by Luiking et al 2009 shows reduced citrulline production and no elevation of NO production in sepsis. The presence of reduced de novo arginine production is suggested, although not measured directly.

**25. Luiking YC, Poeze M, Ramsay G, Deutz NE. Reduced citrulline production in sepsis is related to diminished de novo arginine and nitric oxide production. Am J Clin Nutr. 2009; 89:142-52. [PubMed: 19056593] Clinical study in patients with sepsis that, by using stable isotope techniques, shows the alteration arginine-NO pathway with sepsis. The role of citrulline availability for de novo arginine production is a key finding in this study. 
26. Luiking YC, Hallemeesch MM, van de Poll MC, et al. Reduced citrulline availability by OTC deficiency in mice is related to reduced nitric oxide production. Am J Physiol Endocrinol Metab. 2008; 295:E1315-22. [PubMed: 18697914]

27. Marini JC, Erez A, Castillo L, Lee B. Interaction between murine spf-ash mutation and genetic background yields different metabolic phenotypes. Am J Physiol Endocrinol Metab. 2007; 293:E1764-71. [PubMed: 17925451]

28. van Eijk HM, Luiking YC, Deutz NE. Methods using stable isotopes to measure nitric oxide (NO) synthesis in the L-arginine/NO pathway in health and disease. J Chromatogr B Analyt Technol Biomed Life Sci. 2007; 851:172-85.

29. Luiking YC, Deutz NE. Isotopic investigation of nitric oxide metabolism in disease. Curr Opin Clin Nutr Metab Care. 2003; 6:103-8. [PubMed: 12496687]

30. Wu GY, Brosnan JT. Macrophages can convert citrulline into arginine. Biochem J. 1992; 281(Pt 1):45-8. [PubMed: 1731766]

31. Flam BR, Eichler DC, Solomonson LP. Endothelial nitric oxide production is tightly coupled to the citrulline-NO cycle. Nitric Oxide. 2007; 17:115-21. [PubMed: 17869551]

32. Li P, Kim SW, Li X, et al. Dietary supplementation with cholesterol and docosahexaenoic acid increases the activity of the arginine-nitric oxide pathway in tissues of young pigs. Nitric Oxide. 2008; 19:259-65. [PubMed: 18555806]

33. Zelnickova P, Matiasovic J, Pavlova B, et al. Quantitative nitric oxide production by rat, bovine and porcine macrophages. Nitric Oxide. 2008; 19:36-41. [PubMed: 18456005]

34. Li X, Bazer FW, Gao H, et al. Amino acids and gaseous signaling. Amino Acids. 2009; 37:65-78. [PubMed: 19266154]

35. Wu G, Meininger CJ. Regulation of nitric oxide synthesis by dietary factors. Annu Rev Nutr. 2002; 22:61-86. [PubMed: 12055338]

36. Rajapakse NW, Mattson DL. Role of L-arginine in nitric oxide production in health and hypertension. Clin Exp Pharmacol Physiol. 2009; 36:249-55. [PubMed: 19076168]

37. Wu G, Meininger CJ. Nitric oxide and vascular insulin resistance. Biofactors. 2009; 35:21-7. [PubMed: 19319842]

38. Bryk J, Ochoa JB, Correia MI, et al. Effect of citrulline and glutamine on nitric oxide production in RAW 264.7 cells in an arginine-depleted environment. JPEN J Parenter Enteral Nutr. 2008; 32:377-83. [PubMed: 18596308]

39. Luiking YC, Deutz NE. Biomarkers of arginine and lysine excess. J Nutr. 2007; 137:1662S1668S. [PubMed: 17513444]

40. O'Kane PD, Jackson G, Ferro A. Whole body nitric oxide production is not decreased in patients with coronary atherosclerosis but is inversely related to plasma homocysteine. Atherosclerosis. 2008; 196:574-9. [PubMed: 17662292]

**41. Symons JD, McMillin SL, Riehle C, et al. Contribution of insulin and Akt1 signaling to endothelial nitric oxide synthase in the regulation of endothelial function and blood pressure. Circ Res. 2009; 104:1085-94. [PubMed: 19342603] Well-designed mechanistic study in mice studying signaling pathways for NO production related to a high fat diet and high fatty acid levels. These results may also be applicable to conditions like obesity with impaired vascular function.

42. Wilson JX. Mechanism of action of vitamin C in sepsis: ascorbate modulates redox signaling in endothelium. Biofactors. 2009; 35:5-13. [PubMed: 19319840]

43. Li H, Meininger CJ, Hawker JR Jr, et al. Regulatory role of arginase I and II in nitric oxide, polyamine, and proline syntheses in endothelial cells. Am J Physiol Endocrinol Metab. 2001; 280:E75-82. [PubMed: 11120661]

44. Nijveldt RJ, Siroen MP, Teerlink T, van Leeuwen PA. Elimination of asymmetric dimethylarginine by the kidney and the liver: a link to the development of multiple organ failure? J Nutr. 2004; 134:2848S-2852S. discussion 2853S. [PubMed: 15465798]

45. Durante W, Johnson FK, Johnson RA. Arginase: a critical regulator of nitric oxide synthesis and vascular function. Clin Exp Pharmacol Physiol. 2007; 34:906-11. [PubMed: 17645639] 
46. van de Poll MC, Hanssen SJ, Berbee M, et al. Elevated plasma arginase-1 does not affect plasma arginine in patients undergoing liver resection. Clin Sci (Lond). 2008; 114:231-41. [PubMed: 17708746]

47. Bagnost T, Berthelot A, Bouhaddi M, et al. Treatment with the arginase inhibitor N(omega)hydroxy-nor-L-arginine improves vascular function and lowers blood pressure in adult spontaneously hypertensive rat. J Hypertens. 2008; 26:1110-8. [PubMed: 18475148] 


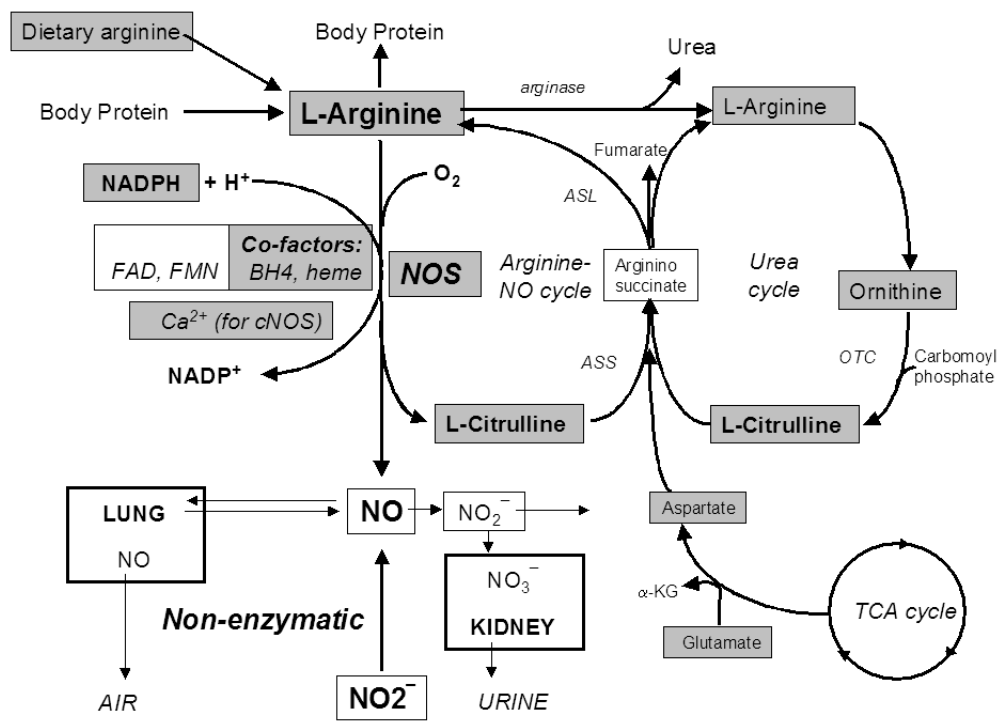

Figure 1. NO synthesis pathway

Schematic overview of the NO synthesis pathway, involving both enzymatic (via NOS; major pathway) and non-enzymatic pathways. L-arginine is converted to NO and citrulline in the presence of NADPH and oxygen. The NOS pathways depend on essential cofactors (BH4, FAD, FMN and heme) for their activity; NOS1 and NO3 are also $\mathrm{Ca}^{2+}$ dependent. De novo arginine production from citrulline involves the enzymes ASS and ASL. Potential factors that can be modified by dietary intake are indicated by a gray background. 


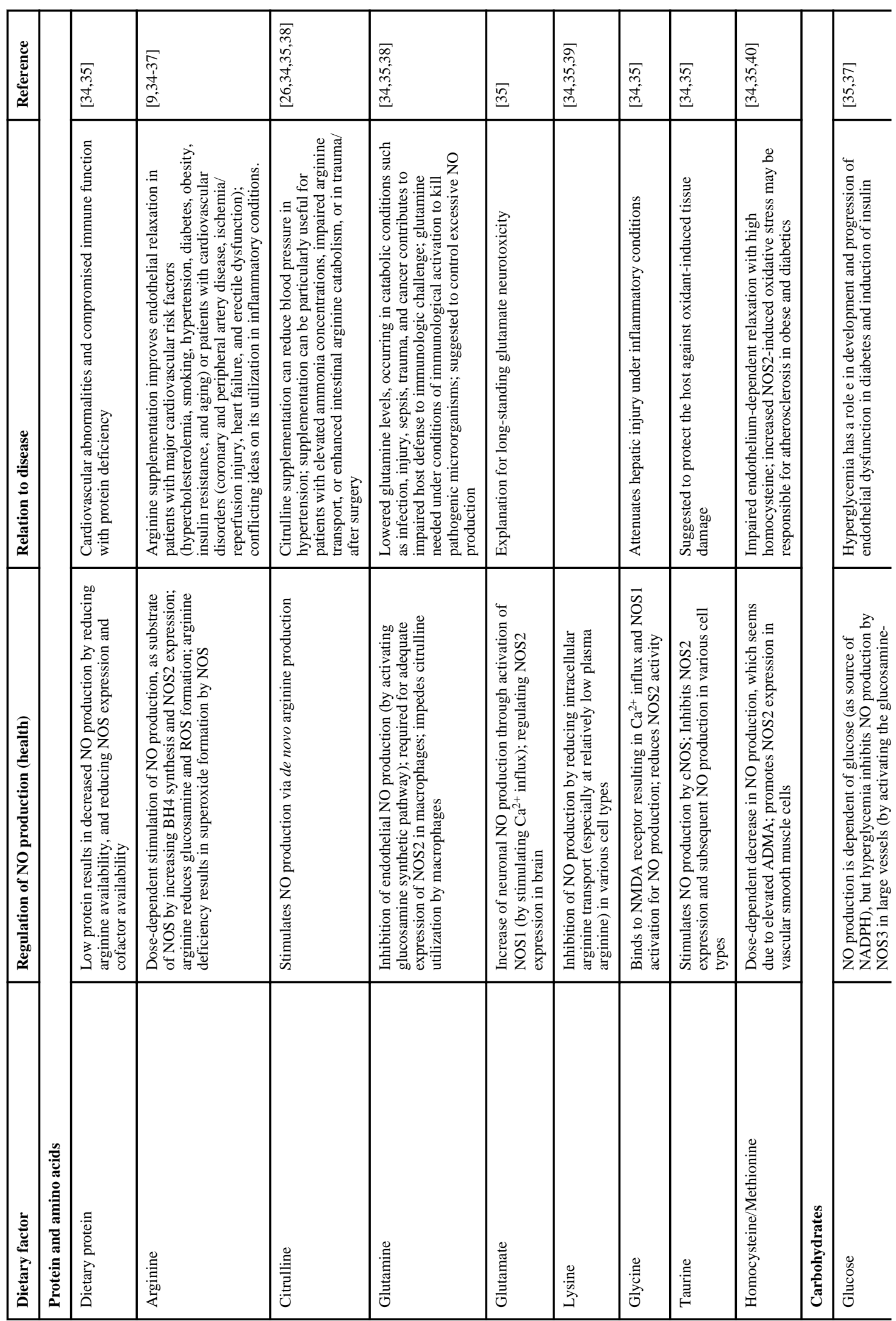




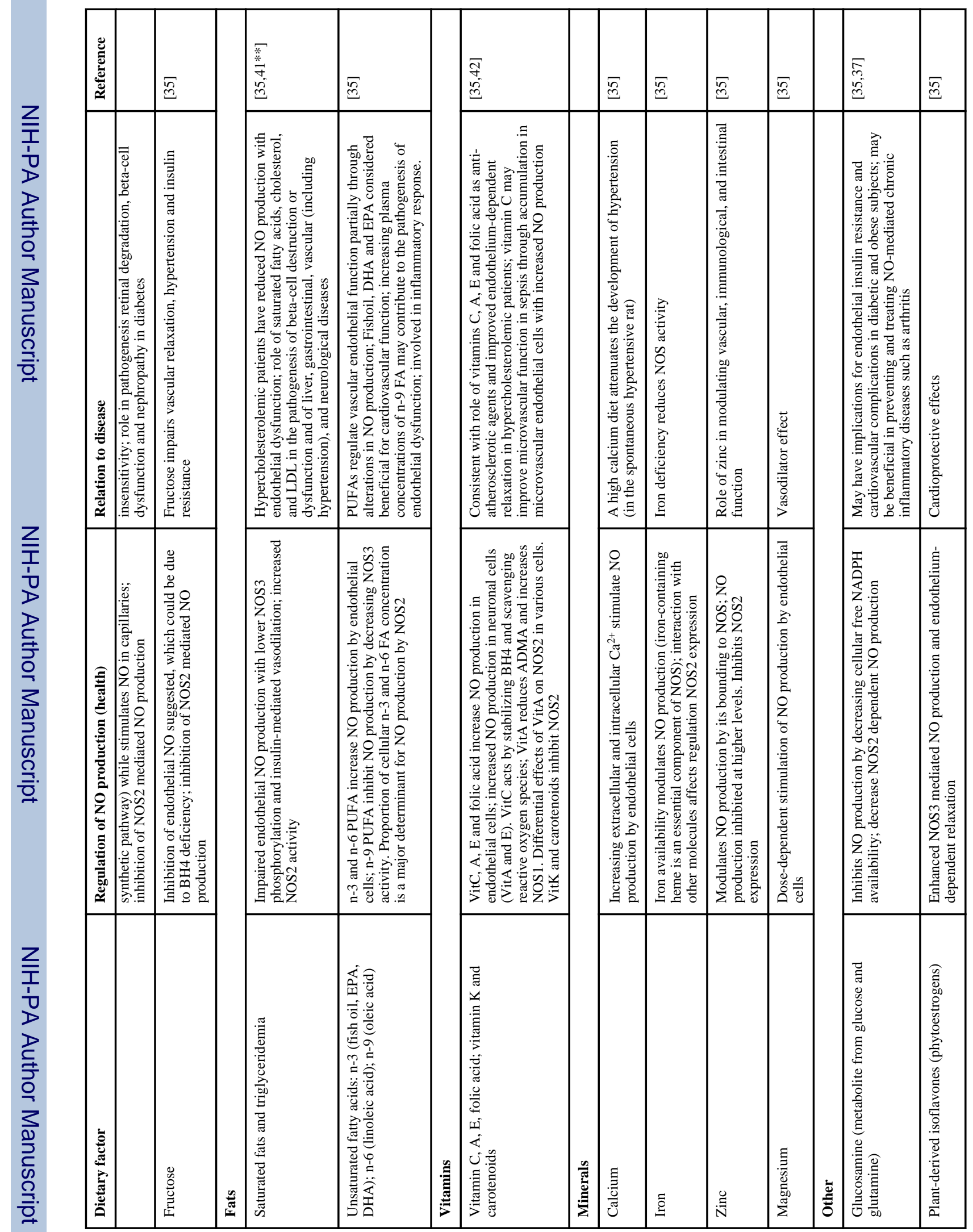


